\title{
MANUEL SERRANO, UN PINTOR COSTUMBRISTA DEL SIGLO XIX
}

\author{
Xavier Moyssén
}

Los temas costumbristas en la pintura mexicana del siglo xIX alcanzaron un desarrollo considerable, tomando en cuenta que se practicó tanto en la provincia como en la capital del país. Esta pintura ofrece aspectos que estuvieron bien lejos de los intereses pictóricos de los artistas académicos; entregados de manera preferente tanto al retrato como a los eternos y desgastados asuntos religiosos, quedaron alejados, por consiguiente, de una identificación con lo propio, con la vida nacional como son los tipos humanos, sus costumbres, gustos y conducta, en los ambientes propios en que se movían. Soy de la opinión que los famosos cuadros de castas, puestos en boga desde mediados del siglo xviII, pueden ser considerados como un antecedente de los cuadros de costumbres, ${ }^{1}$ pues aparte de mostrar las distintas etnias, ofrecen escenas veraces de las formas de existencia que llevaban, desde las vestimentas que portaban, corporaciones y trabajos, las diversiones a que se entregaban, entre ellas la música, hasta los alimentos y frutas que consumían. Son muy variadas las escenas que se registran en los cuadros de castas; así, se llevaron a los lienzos y tablas hasta las agresivas desaveniencias habidas entre las parejas conyugales. ${ }^{2}$ Como sucede en las obras del siglo XIX, existe una notoria desigualdad artística en la producción de los cuadros de castas, debidos en su mayor parte a autores anónimos; mas no desdeñaron hacerlos pintores de cierta fama, como Juan y Nicolás Rodríguez Juárez, Miguel Cabrera o Ignacio María Barreda, entre otros.

Existen en poder de coleccionistas particulares cuatro cuadros de autor anónimo, los cuales se refieren a otros tantos barrios o sitios de la ciudad de

${ }^{1}$ Efraín Castro Morales ofrece novedosas noticias referentes al origen de este tipo de cuadros: ideado, según Andrés de Arce y Miranda, por el "pensamiento ingenioso" del Virrey Duque de Linares, quien ordenó a Juan Rodríguez Juárez que pintara el tema de las castas para enviarlo "al Rey y Corte de España". Véase su estudio en Jamrbuch Für Geschichte, Band 20, número dedicado en homenaje a la memoria del doctor Erwin Walter Palm, pp. 671-690, Böhlav Verlag Köln Wien

${ }^{2}$ El estudio más detenido que se ha realizado sobre estas obras es el de María Concepción García Sáiz: Las castas mexicanas. Un género pictórico americano. Olivetti, 1989. Se recomienda también la lectura de El mestizaje americano, catálogo de la exposición presentada por el Museo de América, Madrid, 1985. 
México. Uno de ellos está dedicado a una vista interior de El Parián, donde aparte de los puestos o "cajones" de los comerciantes, aparecen en primer término los distintos tipos de vecinos de la ciudad (curiosamente en su mayor parte se trata de hombres). En realidad se trata de un cuadro de castas: en la parte posterior de la pintura se da la referencia manuscrita de las veintiún castas que se representan . Como obras costumbristas también pueden ser considerados algunos biombos, como por ejemplo el que se ocupa de un alegre sarao en un espléndido jardín, en el que se encuentra la elegante y privilegiada sociedad virreinal. El biombo pertenece al Museo Nacional de Historia, en Chapultepec. ${ }^{3}$

De nueva cuenta apareció el tema del costumbrismo en la pintura hacia la segunda década del siglo XIX. No deja de ser significativo el que este género de obras lo iniciaran los artistas europeos que arribaron a México una vez que alcanzó su independencia como nación. Cuadros de costumbres los pintaron e incluso los litografiaron, entre otros, Johann Moritz Rugendas, Daniel Thomas Egerton, Johann Salomón Hegi y Edouard Pingret, sin olvidar la valiosa labor de Claudio Linati y Carlos Nebel. Todos, gracias a la veracidad de sus interpretaciones, dieron a conocer en Europa los diferentes tipos de seres que aquí habitaban, así como sus singulares formas de vida; pero a la vez enseñaron a las gentes de aquí a que se conocieran a través del arte pictórico. La lección recibida de los extranjeros no fue desaprovechada por los pintores locales, quienes, al practicarla, la ampliaron y enriquecieron con mayor propiedad, dada su idiosincracia.

Es posible decir que mediante la pintura costumbrista los mexicanos encontraron una forma de mostrarse a sí mismos cómo eran y cuál su conducta una vez que habían dejado atrás su dependencia política de lo español; sus alegrías y también sus pesares quedaron retenidos en esas obras, a las que se puede considerar debidas a un acto de afirmación.

La historia del arte en México ha recogido los nombres de algunos pintores costumbristas; sin embargo, los autores de buena parte de esa producción permanecen en el anonimato, puesto que no siempre firmaron sus obras; menos aún se cuenta con noticias sobre sus vidas y el desarrollo de sus actividades artísticas. Uno de esos pintores fue Manuel Serrano, a quien se rescata mediante este trabajo aprovechando los escasos informes documentales que existen sobre él y, sobre todo, gracias a sus cuadros que hasta nuestros días han llegado.

\footnotetext{
${ }^{3}$ Para el tema de los biombos se recomienda el libro de I eresa Castelló Iturbide, y Marita Martínez del Río de Redo, Biombos mexicanos, México, Instituto Nacional de Antropología e Historia, 1970
} 
Dentro de la corriente costumbrista un caso interesante es el de Manuel Serrano, autor de una importante serie de pinturas y del cual, por desgracia, poco es lo que se sabe. Se ha dicho, sin mayor confirmación, que era español, sin embargo, gracias a Enrique Olavarría y Ferrari sabemos que su nacionalidad era mexicana -lo asentó varias veces; por ejemplo y a propósito de una obra que Serrano hizo del monumento ecuestre de Carlos IV, escribió lo siguiente: "...copiado del original por mi gran amigo el artista mexicano don Manuel Serrano". "Mas no dijo de qué parte del país era oriundo; cabe la posibilidad que lo fuera de Puebla, a juzgar por una tela que firma y dedica en esa ciudad en 1856, misma que tiene las características de la pintura poblana de esa época. Su producción fue extensa y variada en temas, abarca básicamente escenas tomadas de la vida del campo; de manera especial se ocupó de los charros, mas las costumbres de la gente de la ciudad de México no le fueron indiferentes: las retuvo en varias ocasiones. Según las noticias confiables que se poseen, todo parece indicar que Manuel Serrano fue un artista autodidacta, un pintor de "costumbres mexicanas", como se le califica en los catálogos de las exposiciones anuales de la Academia de San Carlos, en las que presentó sus obras, trabajadas éstas tanto al óleo como al pastel. En las exposiciones de 1856,57 y 58 participó como un pintor ajeno a la Academia. Según los archivos de la institución, en 1863 presentó solicitud para estudiar. ${ }^{5} \mathrm{Se}$ puede suponer que en esos años, difíciles para la nación, la vida no le fuera regalada y en consecuencia bastantes problemas debió afrontar, pues diez años más tarde, en 1873, aparece como asistente a las lecciones nocturnas de dibujo que atendía José Obregón. ${ }^{6}$

Como ya se ha anotado, muy poco es lo que se sabe sobre él, se ignora la fecha y lugar de su nacimiento, así como el año en que falleció. En la exposición de 1878 se incluyeron sus cuadros de costumbres. L. Agontía, comentarista de la muestra, escribió lo siguiente:

Con positivo gusto hemos visto también expuestos algunos cuadros originales del maestro Manuel Serrano, muerto hace algunos años y que tanto se distinguió como pintor escenógrafo. Este artista se dedicaba alguna que otra vez a pintar pequeños cuadros de costumbres nacionales que por los asuntos

\footnotetext{
${ }^{4}$ En el tomo segundo de su Reseña histórica del teatro en Mexico, 1583-1911, México, Porrúa, 1961, p. 539 .

${ }_{5}^{5}$ Eduardo Báez M, Guía del archivo de la Antigua Academia de San Carlos, 1844-1847, México, Universidad Nacional Autónoma de México, 1976.

${ }^{6}$ Manuel Romero de Terreros, Catálogo de las exposiciones de la Antigua Academia de San Carlos de México, 1850-1898, México, Universidad Nacional Autónoma de México, 1963, p. 453.
} 
son interesantes, aunque quizá su ejecución no podría resistir a una crítica rigurosa. ${ }^{7}$

Si el comentario se publicó en 1878 y en el mismo se dice que Serrano murió "hace algunos años", es posible pensar que debió fallecer en la séptima década del siglo. Noticia interesante es la que nos informa que también practicaba la escenografía, actividad en la que debió sobresalir, pues en 1865 , por orden de Maximiliano, pintó las decoraciones del teatro que se erigió en el Palacio Imperial para la representación de Don Juan Tenorio, el día 4 de noviembre, ${ }^{8}$ ocasión en la que se estrenó la famosa obra del dramaturgo español José Zorrilla. ${ }^{9}$

La pintura de historia no religiosa no encontró práctica en el ámbito de la Academia; los grandes sucesos que vivió el país, sobre todo durante la Intervención Francesa, no fueron vistos por los artistas académicos, por lo cual puede afirmarse que casi no contamos con cuadros cuya temática sea la historia nacional. Algo semejante ocurrió con la pintura de costumbres: ésta fue ajena a los gustos de la estética institucional; de allí la importancia que guardan las obras debidas a un Agustín Arrieta o un Manuel Serrano, entre otros, pues con ellas contribuyeron a dar un carácter propio a la pintura mexicana del siglo XIX.

No obstante que se ignoran los años de vida de Serrano y el tiempo real que dedicó al ejercicio de la pintura, el número de cuadros que ejecutó debió ser considerable -se afirma lo asentado en atención de los existentes y de las noticias de los que mostró en las exposiciones a las que concurrió. En favor de esa producción, que en su mayor parte nos es desconocida, se transcriben

\footnotetext{
${ }^{7}$ La crítica fue pubicada en La libertad y recogida por Ida Rodríguez Prampolini en Lacrítica de arte en México en el siglo XIX, t. II, México, Universidad Nacional Autónoma de México, 1964, p. 409.

${ }^{8}$ Manuel Romero de Terreros, Paisajistas mexicanos del siglo XIX, México, Universidad Nacional Autónoma de México, 1943, p. 14.

9 Olavarría y Ferrari, en el tomo citado, ofrece varias noticias sobre Serrano y sus actividades como escenógrafo; así nos informa que en 1859 se presentó en el Teatro Principal la obra Un paseo en Santa Anita, para la cual “.... Don Manuel Serrano pintó para esa obra, una muy bonita decoración del Canal de Santa Anita, viéndose en último término el Puente de Jamaica", p. 660. Otra noticia correspondiente a 1864 se refiere a que en el Gran Teatro Imperial se presentó $E l$ Trovador de Giuseppe Verdi, “...para cuya representación pintó Manuel Serrano una magnífica decoración de cárcel con un bellísimo contraste de luz de luna y de luz artificial", p. 684. Luis Reyes de la Maza también recoge noticias de Serrano y la escenografía en sus libros El teatro en México durante el Segundo Imperio (1862-1867), México, Universidad Nacional Autónoma de México, 1959, y Circo, maroma y teatro (1810-1910), México, Universidad Nacional Autónoma de México, 1985. Manuel Serrano debió conocer al pintor italiano Pedro Gualdi, quien vino a México hacia 1838 contratado como escenógrafo teatral; bastante debió aprender de él.
} 
las informaciones de los cuadros que se exhibieron en la Academia, con los comentarios que suscitaron. En 1858:

1. Costumbres mexicanas. Paseando a caballo un guarda del tabaco por un camino, encuentra tendido a un compañero suyo y se detiene para darle auxilio... 2. Paisaje al pastel.... 3. Costumbres mexicanas. Vista de Chapultepec . Al pie de una cabaña rodeada de árboles y sembrado, está un mayoral hablando con una india vendedora; al fondo y a lo lejos se descubre sobre el cerro el fuerte de Chapultepec.... 4. A la orilla de un camino y bajo la sombra de un árbol están descansando unos indios; un sirviente montado en su mula se detiene a observarlos... 5. Las lavanderas. A la orilla de un río están lavando su ropa unas mujeres y con ellas habla el sirviente que, en la orilla opuesta, da de beber a un caballo; un camino se extiende siguiendo el curso del río y a lo lejos se ve una población. ${ }^{10}$

Al año siguiente Manuel Serrano remitió a la Academia cuatro cuadros para su exposición, los cuales fueron colocados en la Gran Sala de Pintura:

1. Costumbres mexicanas. Junto a una cabaña un ranchero platica con unas mujeres: una arboleda se extiende hacia atrás. 2. La pulquería, idem. Agrupados unos bebedores en una pulquería están jugando a la rayuela: en el pavimento han dejado sus cajetes por atender el juego. 3. El jarabe, idem. Unos rancheros y unas chinas están reunidos en un cuarto viendo bailar el jarabe 4 "Los ladrones, idem. Dos ladrones se han apeado de sus caballos y salen al encuentro de un pasajero que va por el camino

Como complemento a la relación de las obras, a continuación se incluyeron estos comentarios:

Como se ve, parece que el apreciable señor Serrano se ha propuesto hacer un estudio formal de las costumbres mexicanas. Dicho artista no puede negarse que hace rápidos adelantos, lo cual es fácil conocer [sic], con sólo recordar, o aún comparar sus diversos cuadros que ha exhibido en las pasadas exposiciones. Nosotros creemos que con el tiempo llegará a conquistar un buen lugar entre los pintores mexicanos. ${ }^{11}$

Las telas de Manuel Serrano que aquí se reproducen nos muestran varios aspectos de los temas que dedicó a sus actividades pictóricas: los charros, escenas del campo y la vida en la ciudad. Sus indudables aciertos en cuanto a los tipos y los ambientes en que desarrollaban sus actividades son más que

\footnotetext{
${ }^{10}$ Romero de Terreros, Catálogos ..., p. 272

${ }^{11}$ Rodríguez Prampolini, op. cit., pp 526-527.
} 
evidentes, así como sus limitaciones, que son las de todo artista de formación autodidacta. Si la técnica y el manejo de los colores de su preferencia lo salvan, por otra parte, no le es desfavorable su expresión mediante el dibujo. Fue un buen observador de los individuos y sus movimientos y, a juzgar por lo que muestran los cuadros, fue sensible a la naturaleza del paisaje, lo cual le favoreció en mucho para sus obras de ambiente campirano.

Entre los tipos nacionales, la figura del charro se ha impuesto hasta alcanzar el nivel de un símbolo. Ningún personaje tan gallardo como él, a quien Justino Fernández definió como el "caballero del campo". Contribuye a marcar su personalidad el atuendo característico que le viste, desde el sombrero hasta las espuelas, sirviendo de complemento el sarape, el machete y la reata. El caballo que monta, a más de ser de "pura clase", también luce sus galas, como son las bridas y la silla apropiada para el jinete. En los festivales, el valor y la destreza del charro quedan de manifiesto en las distintas suertes o acciones con las que compite, ya sea con el lazo o en las lides de la doma de un caballo bruto o de un toro bravo. Lo mismo sucede en una salida de cacería: en los montes y en los valles su presencia se impone.

De las tres obras de Manuel Serrano que se ocupan de los charros ojinetes mexicanos, las dos primeras nos los muestran tal como desarrollaban sus actividades en la época en que los pintó. La figura del charro que monta con energía su caballo es espléndida: con destreza domina al brioso animal. El sombrero que cubre su cabeza es de los llamados de "teja"; fue propio de ese tiempo y lo usaban también los "chinacos", gxupo de guerrilleros que luchó contra la Intervención Francesa. En el segundo cuadro, un grupo de jinetes ha emprendido una marcha entre los montes; el pintor los situó con toda propiedad en el pedregoso camino.

Pareciera ser que en los temas de la charrería Manuel Serrano encontraba especial satisfacción al pintarlos. Su rica experiencia pictórica se encuentra en esas telas; una de ellas es la titulada Cacería del Venado. Una composición ambiciosa por todo lo que reúne y las soluciones adoptadas se halla en esta singular obra, en la que el paisaje es elemento primordial y el problema de la perspectiva está resuelto; así también el movimiento del galope de los caballos y las posturas de los jinetes que van tras la codiciada presa.

Tres animadas escenas referentes a las costumbres de los habitantes del campo son las siguientes: Jugando al tresillo, Los tacos de mole y La china pulquera. En la primera, varios rancheros se entretienen jugando al tresillo con las cartas ante la mirada complaciente de una joven de graciosa figura. Todo lo tratado está pintado con la propiedad que dan el conocimiento y estudio de la realidad, desde las posturas indolentes de los hombres que descansan, hasta los ademanes e interés de los que participan en el juego. 
Algo semejante se puede decir ante la segunda obra, no obstante la sencillez de su composición; el carácter de la ingenuidad que posee lo produce la escena misma. En cuanto al tercer cuadro, éste muestrala maestría que podía alcanzar Serrano, pues bien plantada está entre los dos jinetes la figura de la china que ofrece un cuenco del pulque al charro que no se ha apeado de su montura. El tratamiento de la luz y el color, así como el paisaje del fondo, hacen un todo armónico de esta obra maestra del costumbrismo mexicano del siglo XIX.

La pintoresca escena noctura de la venta de buñuelos, que se supone tiene lugar en la ciudad de México, nos muestra los tipos del pueblo agrupados en plena calle y dedicados a diversas actividades. Sin embargo, el tema central de la pintura es la vendedora de buñuelos, quien los prepara ante la mirada golosa de los niños; en la composición sobresale también el vendedor de trastos de barro cocido. En un plan ambicioso se colocó Serrano para enfrentarse al problema de la luz artificial que ilumina la parte central de la escena, luz que proyecta las sombras de los hombres, mujeres y niños allí reunidos. Dada su propiedad, el cuadro se presta bien para ilustrar ciertos relatos de los escritores costumbristas de la época, como un José Tomás de Guéllar o un Guillermo Prieto.

El cuadro de La cocina, no obstante que acusa la presencia de Edouard Pingret y Agustín Arrieta, quienes se ocuparon también del asunto, no está exento de originalidad; Manuel Serrano la logró en la composición y en el carácter de los personajes incluidos: las dos mujeres guardan la propiedad de las actividades que desempeñan; interesante es la figura del aguador, con su vestimenta y las grandes ollas que carga. El ambiente de la cocina con todos sus enseres y la forma de conservarlos habla de una manera de ser perteneciente a un pasado quizá no del todo perdido en la provincia, a pesar de los adelantos que ofrece el mundo de hoy.

En relación con la vida en la ciudad deben inciuirse las dos grandes telas que pintó al óleo y firmó en 1851 sobre La Catedral de México. El gran monumento arquitectónico sobresale en el área pictórica; está trabajado con una delicada y uniforme entonación marxón claro, misma que invade la portada de la iglesia del sagrario, en sustitución del color rojo del tezontle. Los árboles y las cadenas que rodeaban el atrio de la catedral le dan al conjunto un carácter especial; sobresale el volumen de la Piedra del Sol, en la base de la torre donde se mantuvo durante años. ${ }^{12}$

\footnotetext{
${ }^{12}$ Hasta donde mi información alcanza, los dos cuadros, semejantes en tamaño, son desconocidos, no se han publicado; pertenecen a colecciones particulares de la ciudad de México
} 
Manuel Serrano no fue indiferente a la pintura de naturalezas muertas o bodegones; existen varios cuadros que le acreditan como practicante de este género de obras. Aquí solamente habré de ocuparme de una que no ofrece ninguna duda respecto a su autoría, ya que en el borde de la mesa pintó esta larga inscripción: "Manuel P. Serrano pintó y dedicó al Sr. D. Romualdo Zamora. Puebla enero 9 de $1856 . "$

La composición de esta naturaleza muerta es muy semejante a las pintadas por Agustín Arrieta, lo cual plantea el siguiente problema: ¿quién fue el introductor de este tema en la pintura poblana de la época, Serrano o Arrieta? Las canastas con verduras, los objetos de cristal y porcelana, hasta la inclusión de la graciosa figura de un gato blanco, sentado, todo es muy parecido a los famosos cuadros de Agustín Arrieta, quien, entre paréntesis, solamente firmó algunas telas, mas la mayoría las dejó sin fechar. ${ }^{13}$

Manuel Serrano es una figura clave entre los practicantes del género costumbrista del siglo xIx, es tan importante como el ya citado Agustín Arrieta, a pesar de que no se ocupó preferentemente de la pintura de bodegones. Su lugar está entre los artistas que vieron en lo que es propio del país una fuente digna de creación, por ejemplo con sus cuadros de charrerías; él vino a ser, así, el antecedente más directo de Ernesto Icaza, el "charro pintor". ¿Cuántos personajes como Serrano faltan por rescatar de ese siglo fundamental en nuestra historia? No lo sé, pero estoy persuadido de que investigaciones futuras los descubrirán.

Las fotografías que ilustran este estudio se deben a la gentileza del señor don Benito Zamora, a quien manifiesto aquí mi agradecimiento. La que corresponde a la catedral fue tomada por el señor Pedro Cuevas, del Instituto de Investigaciones Estéticas.

${ }^{13}$ Esta obra de Serrano está publicada en el número 41 de la revista Artes de México, correspondiente a 1962 
DOI: http://dx.doi.org/10.22201/iie.18703062e.1993.64.1669

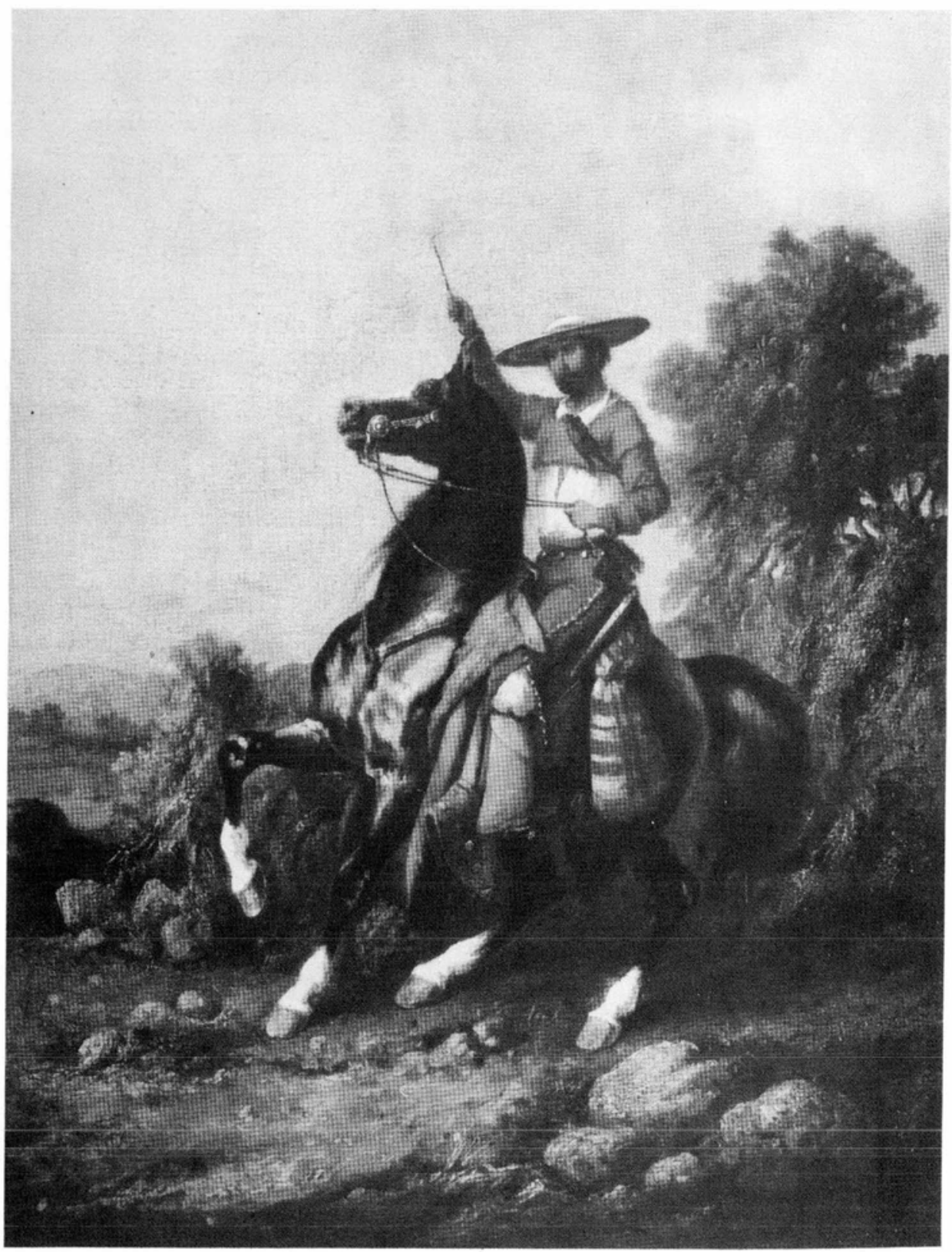

1. Manuel Serrano. Un charro. 
DOI: http://dx.doi.org/10.22201/iie.18703062e.1993.64.1669

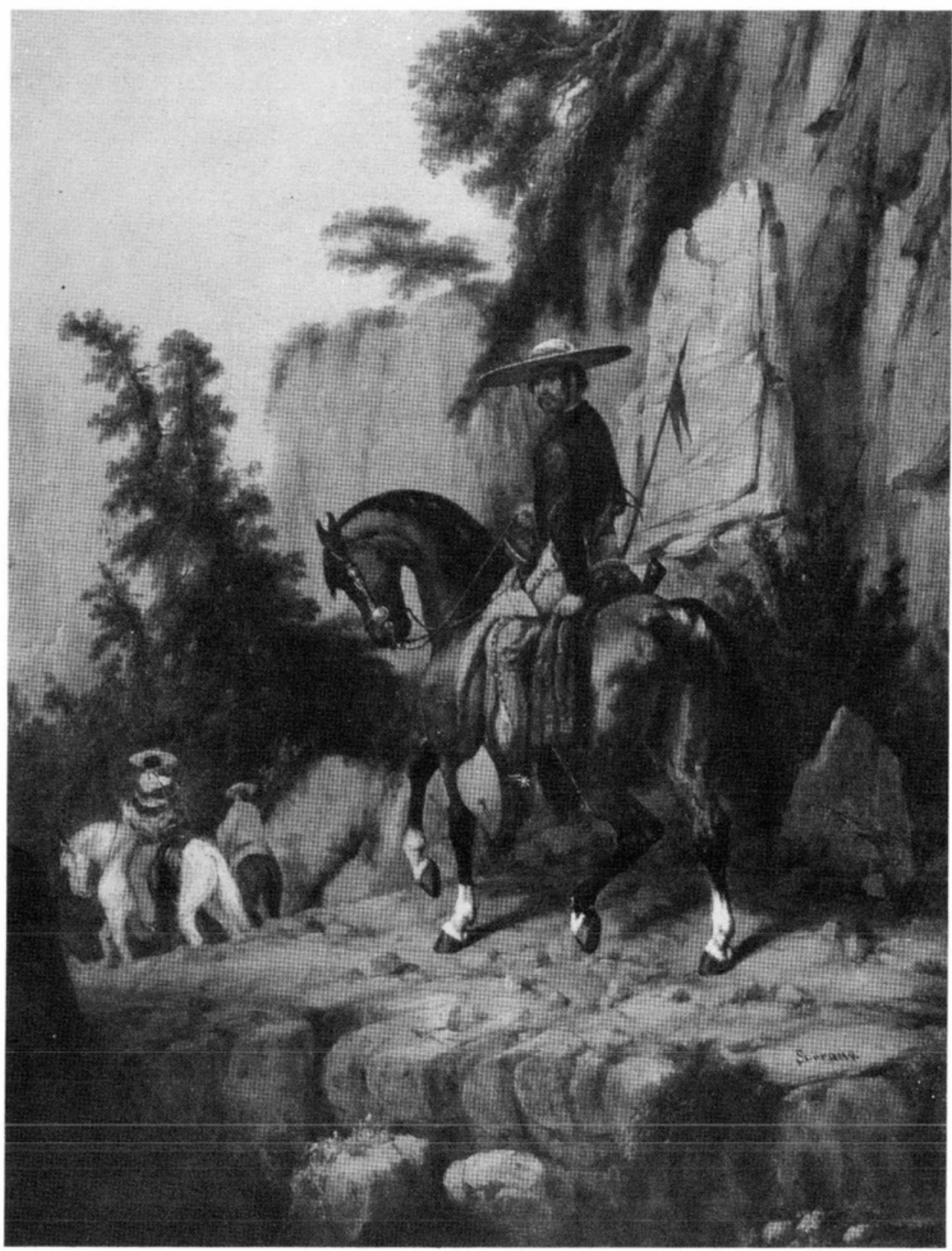

2. Manuel Serrano. Los chinacos. 
DOI: http://dx.doi.org/10.22201/iie.18703062e.1993.64.1669

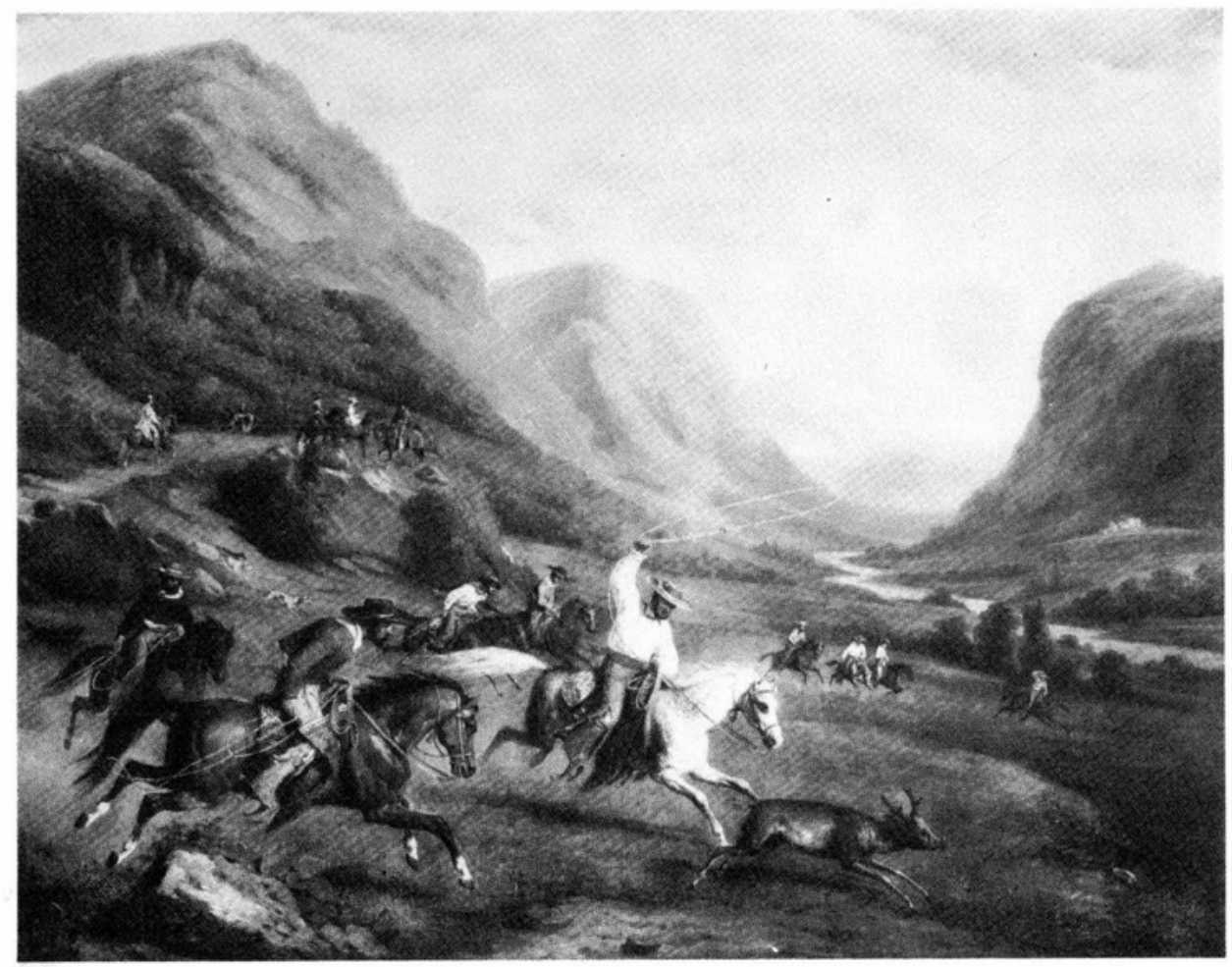

3. Manuel Serrano. Cacería del venado. 
DOI: http://dx.doi.org/10.22201/iie.18703062e.1993.64.1669

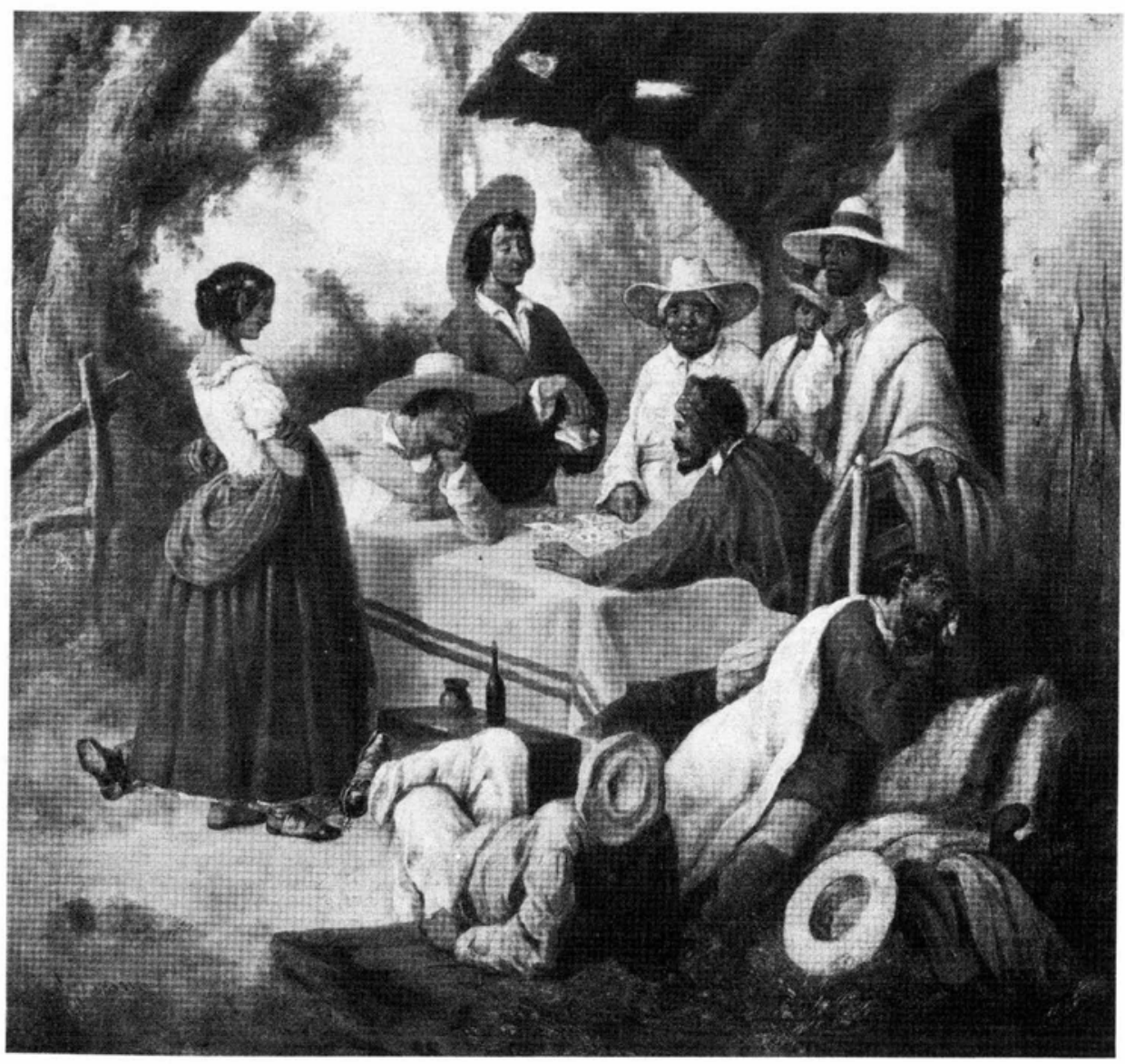

4. Manuel Serrano. Jugando al tresillo. 
DOI: http://dx.doi.org/10.22201/iie.18703062e.1993.64.1669

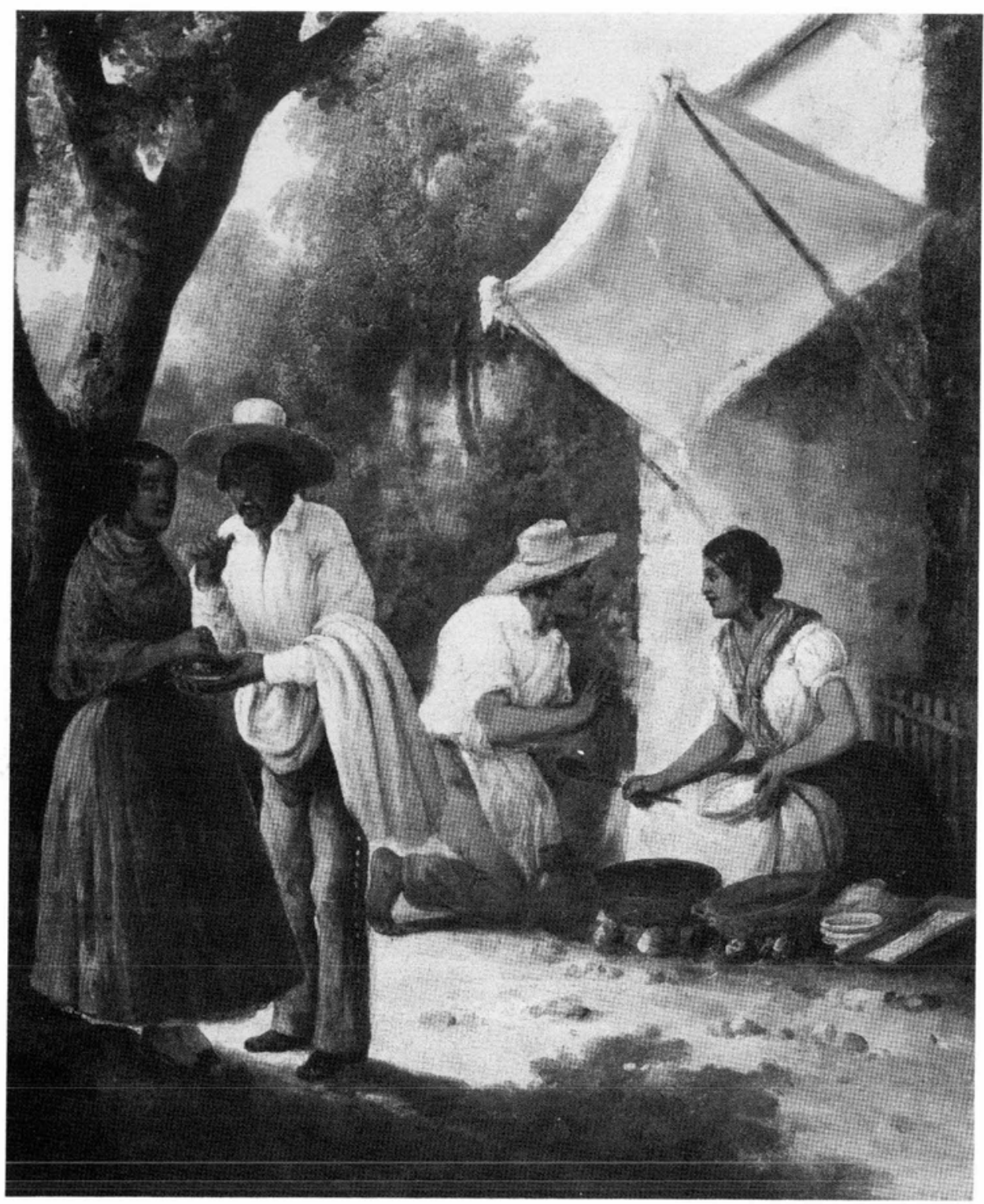

5. Manuel Serrano. Los tacos de mole. 
DOI: http://dx.doi.org/10.22201/iie.18703062e.1993.64.1669

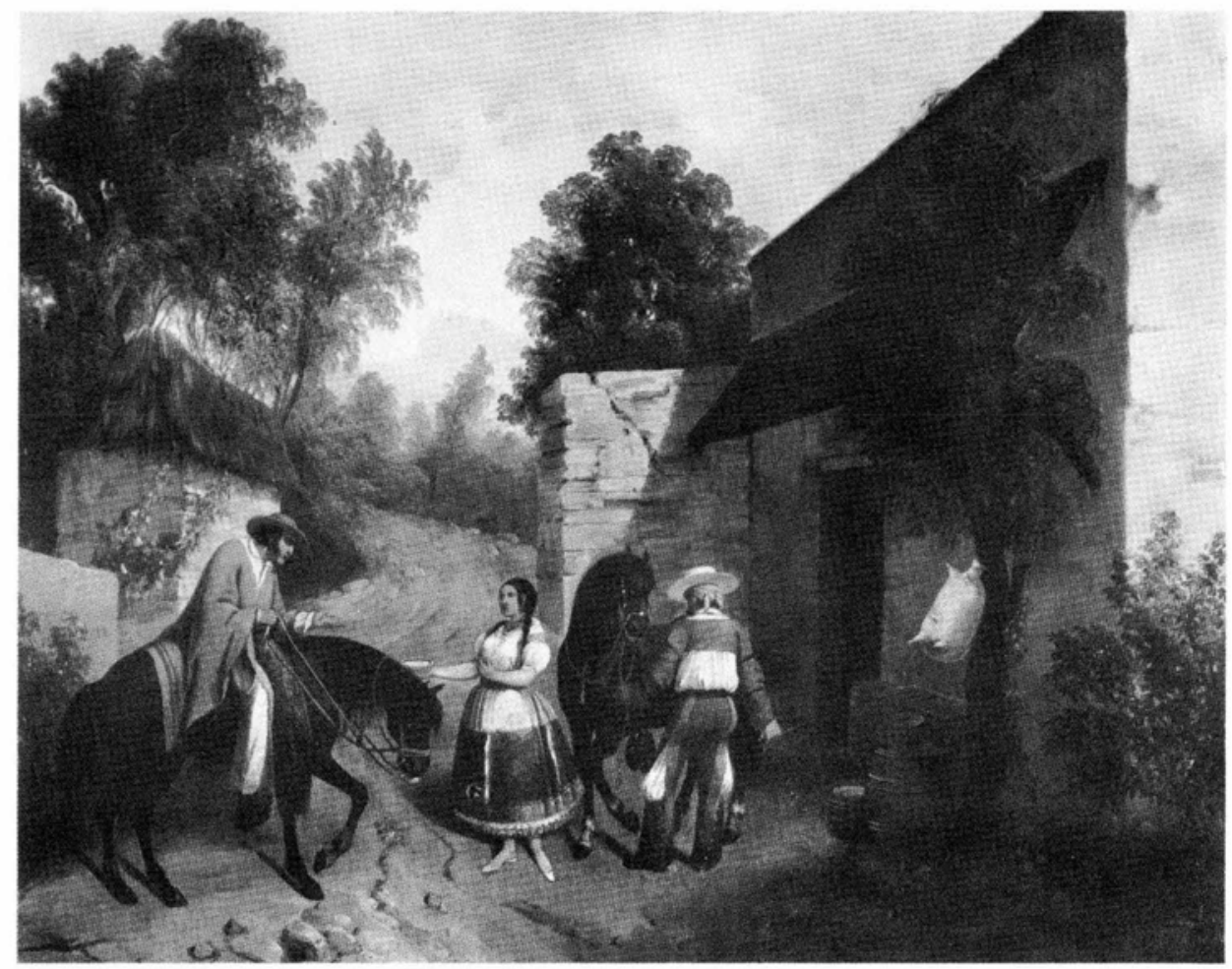

6. Manuel Serrano. La china pulquera. 


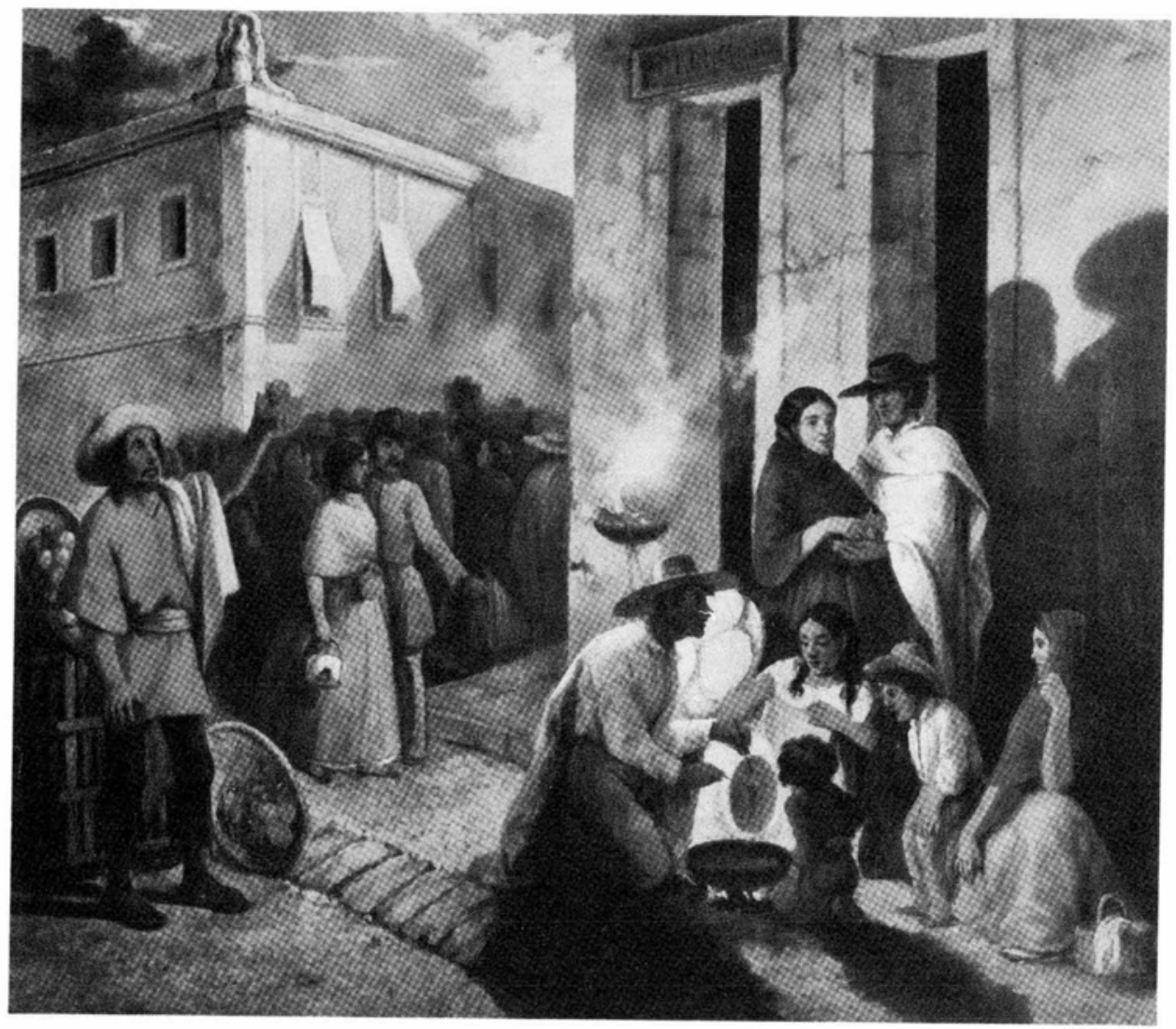

7. Manuel Serrano. La venta de buñuelos. 


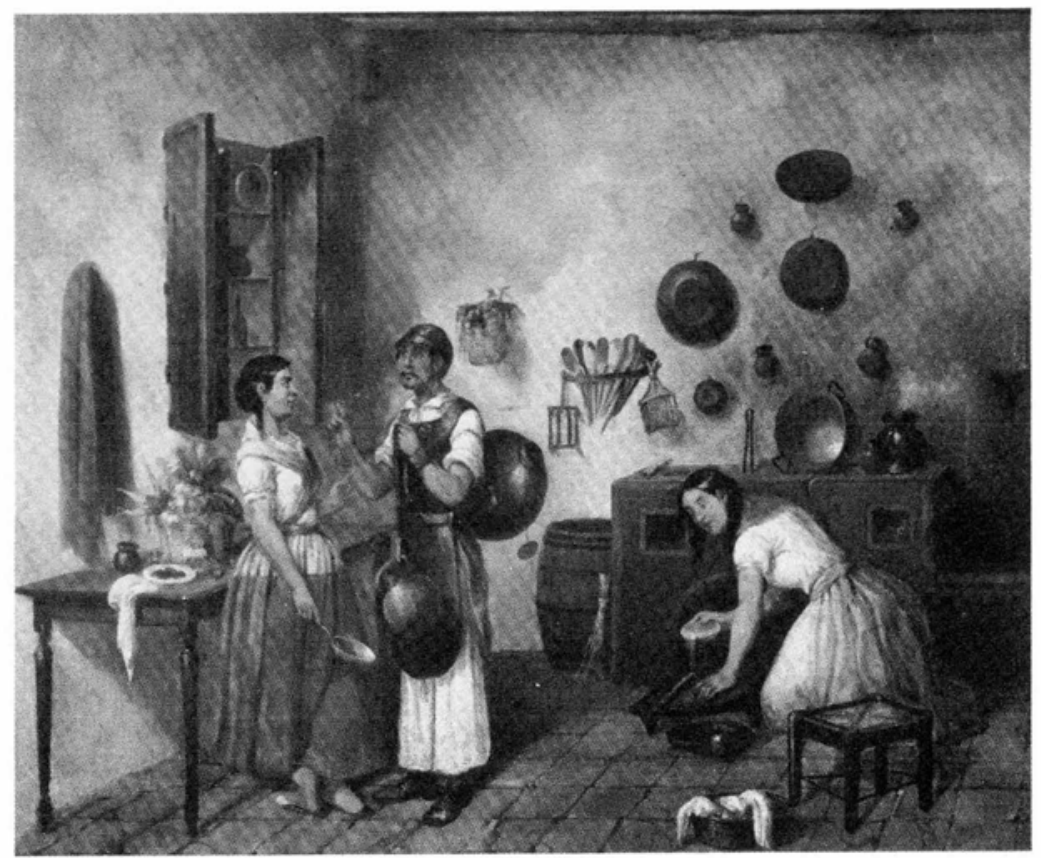

8. Manuel Serrano. La cocina.

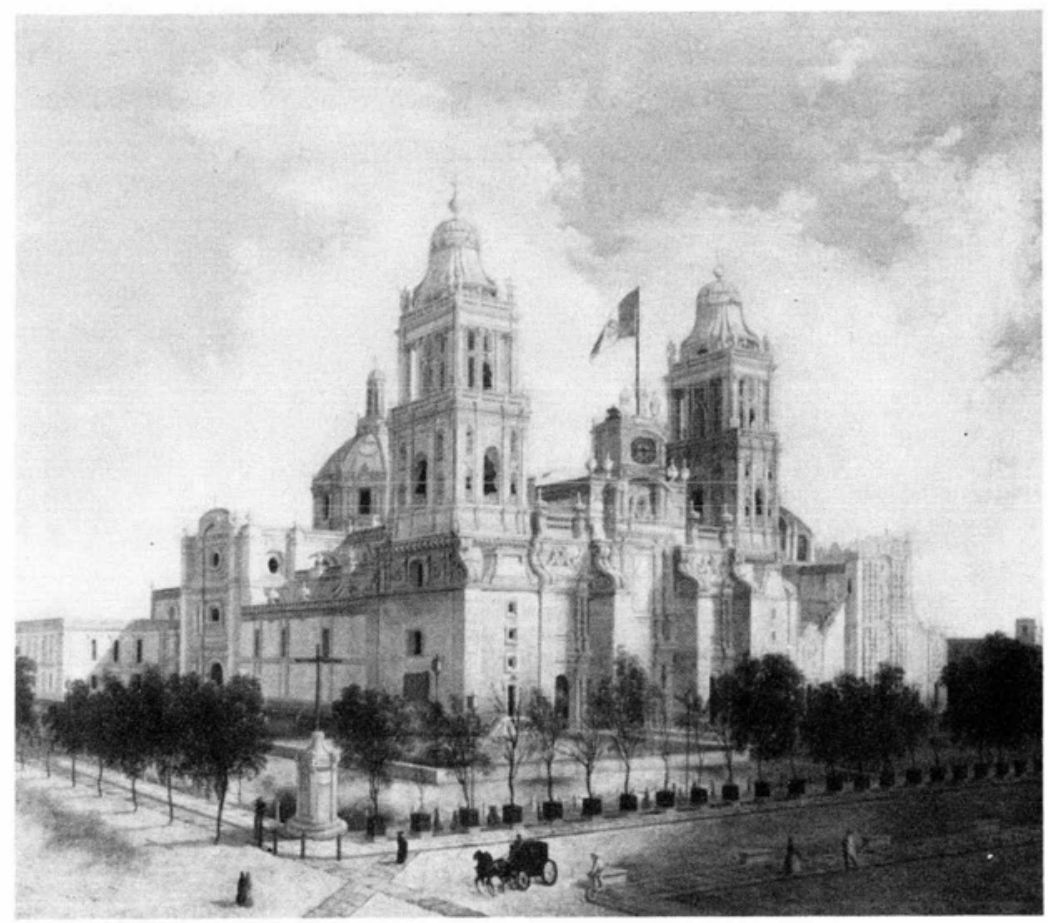

9. Manuel Serrano. La Catedral de México. 